Journal of Engineering and Applied Sciences 14 (Special Issue 7): 9959-9965, 2019

ISSN: 1816-949X

(C) Medwell Journals, 2019

\title{
The Effect of Combine Harvester Speed, Threshing Cylinder Speed and Concave Clearance on Threshing Losses of Rice Crop
}

\author{
Almosawi Abdul-Aziz Abbas \\ Al-Furat Al-Awsat Technical University, Kufa, Iraq
}

\begin{abstract}
$\overline{\text { Abstract: This study was conducted to investigate the combine harvester speed, threshing cylinder speed and }}$ concave clearance on threshing losses and some related parameters during harvesting the local rice variety forate 39. The experiment was designed as a split-split-plot design on the basis of RCBD with three replicates. A class dominator 68 sec combine harvester was used to conduct all the trails. The results revealed that all factors of the study had a significant effect on threshing losses at $\mathrm{p} \leq 0.01$. A smallest concave clearance, highest threshing cylinder speed and lowest combine advancement resulted in a lower threshing losses. While the highest value of losses achieved at a large concave clearance, lowest threshing cylinder speed and highest combine advancement. The results also suggested a strong correlation relationship between the study parameters. Regarding the threshing loss parameter, it was significantly and positively correlated with the feed rate while negatively correlated with threshing index at $\mathrm{p} \leq 0.01$.
\end{abstract}

Key words: Rice, threshing losses, combine harvester speed, threshing cylinder speed, concave clearance, threshing index, feed rate

\section{INTRODUCTION}

Threshing is one of the basic function of combine harvester. It occurs at the front of the cross sectional area of the combine threshing unit (cylinder and concave). The phenomenon on which rice threshing unit works is impact threshing theory. The key of threshing components of impacting threshing unit is the spike teeth that were bolted on the cylinder and the concave. The power required for threshing is to overcome the contact force between stalks and grain ears with the threshing teeth. The threshing clearance spreads from the root of threshing tooth to the top of concave grate (Fu et al., 2018). The mentioned power and contact cause a significant amount of losses. The acceptable losses for small grains when harvesting with combine is $3-5 \%$ worldwide, so that, $0.5-2 \%$ is attributed to platform of the combine and $0.9-1.8$ is ascribed to the back of the combine (Rad, 2004). Ahmad et al. (2017) confirmed that conventional combine harvester gave $5-12 \%$ shattering losses and 3-7\% threshing losses for the standing crop while the lodged crop gave more than that percent. Understanding the impact of combine harvester speed, feeding rate, threshing cylinder speed, cylinder concave clearance and threshing index is of a very great importance for reducing rice losses and rice grain quality. Mohd et al. (1997) investigated the impact of ground speed and threshing cylinder speed on combine losses, the result of this study revealed that the lowest losses associated with ground speed of $5.5 \mathrm{kmh}^{-1}$ while the lowest losses related to threshing unit was at cylinder speed of $900 \mathrm{rpm}$. Taylor and Schroch (1995) revealed that cylinder speed determine the amount of grain threshed out of the panicles and grain damage. Under threshing and over threshing are the two terms used by the same researchers to describe the effect of cylinder speed and concave clearance. Olaye et al. (2016) reported that grain losses increased as the cylinder speed increased. The grain losses ranged from $0.88 \%$ at $600 \mathrm{rpm}$ to $4.23 \%$ at $1200 \mathrm{rpm}$, however, no significant difference were reported between 600 and $800 \mathrm{rpm}$. These results do not comply with results of other researchers.

Al-Mosawi (2007) conducted a study to determine the effect of combine speed, threshing cylinder velocity and cylinder concave clearance on the loss of threshing unit for the local rice variety Anbar. The result indicated that the small clearance was more influential than the other machine parameters in reducing the rate of loss and the reason for that it reduced the plant mass passing through the space between the concave and cylinder which in turn increased the threshing severity. Loewer et al. stressed that the factor of feeding rate is a major factor in determining the amount of combine threshing losses. They also pointed out that the percentage of loss increased from $4 \%$ to more than $7 \%$ at 3 and $6 \mathrm{kgsec}^{-1}$ feeding rate, respectively. These percentage of losses are considered very high, if compared to the reported loss percentage during the natural harvesting conditions.

Ahuja et al. found that the cylinder speed and feeding rate were significant on non-collectable losses at $5 \%$ level of confidence the maximum loss was observed at cylinder speed and feeding rate equal to $16.61 \mathrm{msec}^{-1}$ and 5.52 th $^{-1}$, respectively. 
Oduma et al. (2015) used the threshing index as an indicator for the threshing intensity which was expressed in $\mathrm{kWkg}^{-1}$. The results of this research indicated that the higher threshing index the lower threshing intensity. It is worth mentioning that the researchers defined the threshing index as the product of grain recovery range, capacity utilization and threshing efficiency expressed in decimal. In a comprehensive study dealt with the threshing index, Miller considered the threshing index as a mean of describing the flail characteristics of a spike tooth threshing cylinder. In another word, how many times are the combine tooth cylinder striking the crop in $1 \mathrm{~m}$ of the combine forward movement. The review of previous literature indicates that a small number of studies dealt with combine harvester threshing losses, therefore, this study aimed to investigate the effect of three levels of concave clearance, three levels of threshing cylinder speed and three levels of combine harvester field speed on threshing losses and some related parameters.

\section{MATERIALS AND METHODS}

The study was conducted at Almishkab rice research station in the field condition to determine the threshing cylinder losses with three related parameters height of cut, threshing index and harvesting feed rate. A crawler wheel adapted Claas dominator $68 \mathrm{sec}$ combine harvester of German origin was used to perform the trials. The combine harvester was equipped with $78.33 \mathrm{~kW}$ diesel engine and spike teeth threshing cylinder and concave system which usually used to strip rice panicles. The technical parameters of the investigated combine harvester were demonstrated in Table 1.

Crop physical properties: A field and laboratory study on ten branches of the forate 39 rice variety plant in 54 random sites in the field of experimentation was performed to determine some physical characteristics of the processed crop. The means of these physical properties are shown in Table 2.

Statistical analysis: The experiment was designed as a split-split-plot design on the basis of Randomized Complete Block Design RCBD to determine the threshing cylinder losses with some related parameters (rice residue height, feed rate and threshing index) under the effect of different combine field speeds, different threshing cylinder speeds and different concave clearances. The main plot was assigned to the concave clearance with the levels of $(2,1.5,1.25 \mathrm{~cm})$, the sub plot was defined to the threshing cylinder speed with the levels of $(700,900$, $1100 \mathrm{rpm}$ ) while the sub-sub plot was given to combine harvester speed with levels $\left(2.17,3,3.49 \mathrm{kmh}^{-1}\right)$. The GenStat Twelfth Edition Software Program were used to
Table 1: Technical parameters of the investigated combine harvester

\begin{tabular}{ll}
\hline Parameters & Measure unit and values \\
\hline Header engagement width & $4.27 \mathrm{~m}$ \\
Concave length & $103 \mathrm{~cm}$ \\
Threshing cylinder diameter: & \\
Concave bars No. & 15 \\
Without threshing spike teeth & $34 \mathrm{~cm}$ \\
Concave teeth rows & $2 \mathrm{rows}$ \\
With the threshing spike teeth & $48 \mathrm{~cm}$ \\
Concave row teeth & $19 \mathrm{spike}$ teeth per row \\
Cylinder bars No. & 9 \\
Spike tooth length & $6 \mathrm{~cm}$ \\
Cylinder teeth No. & $13 \mathrm{for}$ each bar \\
Spike tooth width & $3 \mathrm{~cm}$ \\
Cylinder length & $102 \mathrm{~cm}$ \\
\hline
\end{tabular}

process the Analysis of Variance (ANOVA) in order to analyze the experiment data and means of the results were compared according to the Least Significant Difference (LSD) at 0.05 .

Rice residue height (height of cut): The rice height of cut samples were measured in three random places for each treatment. The sampling places were selected by throwing a square metal immediately after completion of each harvest treatment and several readings of the residue height were taken inside the metal square. The readings were summed and averaged to represent one treatment replicate. It should be noted that we have suffered during the rice residue height sampling because the ground on which the thrown square is located is uneven. Therefore, so, many samples have been taken for rice residue that have the same level of ground surface within the measurement of square area to reduce the variation.

Feed rate: According to Andrews et al. (1993), Siebenmorgen et al. (1994) and Jain and Grace feed rate is the weight of grain mass and material other than grain (Mog) that pass through the combine harvester feeding track. However, the same researchers agreed that feed rate can be determined by the height at which rice crop cut, forward speed of the combine, header width and density of the rice crop. Therefore, three assumption must be considered before the development of the mathematical relationship used to calculate the feed rate $\mathrm{Q}_{0} \mathrm{kgsec}^{-1}$. These are the cutting occurred over the entire width of the cutter bar $\mathrm{C}_{\mathrm{w}} \mathrm{m}$ which represent the distance between the header crop dividers, regarding this research the actual width of cut was utilized. The combine harvester cut the rice straw at specific fixed cutting speed $V_{m} \mathrm{msec}^{-1}$. The average rice straw weight per square meter $\mathrm{A}_{\mathrm{rs}} \mathrm{kgm}^{-2}$ is constant all over the area to be harvested. The amount of straw cut per time unit and fed to the combine (feed rate) was calculated as follow:

$$
\mathrm{Q}_{0}\left(\mathrm{~kg} \cdot \mathrm{sec}^{-1}\right)=\mathrm{A}_{\mathrm{rs}}\left(\mathrm{kg} \cdot \mathrm{m}^{-2}\right) \cdot \mathrm{V}_{\mathrm{m}}\left(\mathrm{m} \cdot \mathrm{sec}^{-1}\right) \cdot \mathrm{C}_{\mathrm{w}}(\mathrm{m})
$$


J. Eng. Applied Sci., 14 (Special Issue 7): 9959-9965, 2019

Table 2: Some physical properties of Forate 39 rice variety

\begin{tabular}{|c|c|c|c|c|c|c|c|}
\hline $\begin{array}{l}\text { Plant density } \\
\left.\text { (Plant.m }{ }^{-2}\right) \\
\end{array}$ & $\begin{array}{l}\text { Plant height } \\
(\mathrm{cm})\end{array}$ & $\begin{array}{l}\text { Panicle length } \\
(\mathrm{cm})\end{array}$ & $\begin{array}{c}1000 \text { grains } \\
\text { (mass/g) }\end{array}$ & $\begin{array}{l}\text { No. of empty grains } \\
\text { (in } 10 \text { branches) }\end{array}$ & $\begin{array}{c}\text { No. of filled grains } \\
\text { (in } 10 \text { branches) }\end{array}$ & $\begin{array}{c}\text { Infertility rate } \\
(\%)\end{array}$ & $\begin{array}{c}\text { Grain yield } \\
\left(\mathrm{kgha}^{-1}\right)\end{array}$ \\
\hline 379 & 74.375 & 19.145 & 23.918 & 116.695 & 809.437 & 13.895 & 6596.3 \\
\hline
\end{tabular}

Regarding the equation, the relationship between the height of cut, the mass of grain and Material other than grain (Mog) above the cut for the treated rice crop density was determined according to the data found in the height of cut parameter.

Threshing index: Threshing index represents the number of strikes directed by the spike tooth cylinder to the rice stalks in $1 \mathrm{~m}$ of the combine harvester movement during harvesting. Another term also requires clarification which is the total flail rate. This term is a combination of the flail of the threshing cylinder and the threshing cylinder speed. Flail of the threshing cylinder is defined as the outer surface area of the rotating threshing cylinder that contribute into the threshing effort. All of these terms formed the components of the following equation which was revealed by Miller to calculate the threshing index:

Total flail rate m.sec ${ }^{-1}$

$\mathrm{Ti}=$ Combine harvester forward speed $\mathrm{m} \cdot \mathrm{sec}^{-1}$

Whereas, $\mathrm{Ti}=$ Threshing index.

Rice threshing losses: Rice threshing occurs when rice straws projected to high impact from the threshing cylinder. This kind of threshing has a possibility of rice threshing losses as a result of incomplete detach of kernels from the rice panicles. To assess this kind of loss, fifty parts of the processed rice stems containing either unthreshed panicles, semithreshed panicles, clusters or spikelet were picked randomly from the material discharged out of the straw walker. The remaining grains on the collected strews were threshed manually, weighed and recorded to represent threshing losses sample in fifty stems. This sample was replicated three times and combined with the rice plant density to calculate threshing losses in $\mathrm{kgha}^{-1}$ using the following equation (Tang et al., 2016):

$$
\begin{aligned}
& \mathrm{R}_{\mathrm{pd}}\left(\mathrm{P} \cdot \mathrm{m}^{-2}\right) \cdot \mathrm{K}_{\mathrm{w}}(\mathrm{g} \text { of } 50 \text { plants }) \cdot 10000\left(\mathrm{~m}^{2} \cdot \mathrm{ha}^{-1}\right) \\
& \text { TL.kg.ha' } \\
& \text {-1 }=1000\left(\mathrm{~g} \cdot \mathrm{kg}^{-1}\right) \cdot 50 \text { plants }
\end{aligned}
$$

Where:

TL : Threshing Losses $\left(\mathrm{kgha}^{-1)}\right.$

$\mathrm{R}_{\mathrm{pd}}$ : Rice plant density (plant $\mathrm{m}^{2}$ )

$\mathrm{K}_{\mathrm{w}}$ : Kernel weight of 50 (plants g)

\section{RESULTS AND DISCUSSION}

Rice residue height: The Analysis of Variance (ANOVA) showed that the combine harvester speed is the only factor among the experimental factors which significantly effect the rice residue height at $\mathrm{p} \leq 0.001$. The averages of the rice residue height as well as the binary and triple interactions are summarized in Table 3. The table shows that the average of rice residue height significantly varied among levels of combine harvester speed. But it was not significantly different within each level of combine harvester speed.

There was a gradual decrease in rice residue as the rate of combine harvester speed increased. It was due to the mismatch between the combine harvester speeds 2.17 and $3.0 \mathrm{kmh}^{-1}$ and the speed of the combine reel or due to improper reel index for the mentioned speed levels which were 2.39 and 1.72 , respectively at $24 \mathrm{rpm}$ reel speed.

In order to utilize the differences in rice residue height in this study, a normalizing procedure was used to relate the residue height to the final plant height at the time of harvesting. The Residue height ratio (Rhr) was determined by dividing the height of cut (measured from soil surface) by the final plant height Table 2 . The height of residue ratios were $41.0,39.0$ and $37.0 \%$ for the combine speeds 2.17, 3.0 and $3.49 \mathrm{kmh}^{-1}$, respectively. These results are consistent with the results found by Al-Mosawi (2007) in terms of principle. The binary interaction between the cylinder speed and concave clearance was not significant while the other interactions were significant. This finding indicates that the effect of the cylinder speed and concave clearance were not in direct effect with residue height but assist the most influential factor that is the speed of the combine harvester. The triple interaction was significant for the same reason mentioned earlier.

Threshing index: Statistical analysis of the data showed that the combine harvester speed and threshing cylinder speed had a significant effect at $\mathrm{p} \leq 0.01$ on threshing index while the concave clearance factor had no clear effect. The testing variables, results and least significant differences of means at $\mathrm{p} \leq 0.05$ are shown in Table 4 . The results indicated that when combine harvester speed changes the threshing index changes too but in opposite manner. So when the combine harvester speed decreases, the threshing index increases and vice versa. Furthermore, the rate of change in threshing index is not the same as the combine changing the levels of speed, suppose the change in the combine speed is an increase of $0.5 \mathrm{kmh}^{-1}$ from the speed levels $2.17-3.49 \mathrm{kmh}^{-1}$ this increase in combine harvester speed changed the threshing index by 81.62 and 47.75, respectively for the high level of the threshing cylinder speed $1100 \mathrm{rpm}$. This 
J. Eng. Applied Sci., 14 (Special Issue 7): 9959-9965, 2019

Table 3: The means of rice residue height

\begin{tabular}{|c|c|c|c|c|c|}
\hline \multirow[b]{2}{*}{ CL (cm)/CS (rpm) } & \multicolumn{3}{|l|}{ Hs $\left(\mathrm{kmh}^{-1}\right)$} & \multirow{2}{*}{$\begin{array}{l}\mathrm{CL} \times \mathrm{Cs} \\
\mathrm{LSD}=\mathrm{Ns}\end{array}$} & \multirow{2}{*}{$\begin{array}{l}\text { CL means } \\
\text { LSD }=\text { Ns }\end{array}$} \\
\hline & 2.17 & 3.0 & 3.49 & & \\
\hline \multicolumn{6}{|l|}{2.0} \\
\hline 700 & 30.67 & 28.67 & 27.33 & 28.89 & 29.00 \\
\hline 900 & 31.0 & 29.00 & 27.33 & 29.11 & \\
\hline 1100 & 31.0 & 29.67 & 26.33 & 29.0 & \\
\hline \multicolumn{6}{|l|}{1.5} \\
\hline 700 & 28.67 & 28.33 & 27.0 & 28.0 & 28.56 \\
\hline 900 & 29.67 & 28.67 & 28.69 & 29.0 & \\
\hline 1100 & 30.33 & 28.67 & 27.0 & 28.67 & \\
\hline \multicolumn{6}{|l|}{1.25} \\
\hline 700 & 31.0 & 28.00 & 27.33 & 28.78 & 28.78 \\
\hline 900 & 29.33 & 29.00 & 27.67 & 28.67 & \\
\hline 1100 & 30.0 & 29.33 & 27.33 & 28.89 & \\
\hline Hs means & 30.19 & 28.81 & 27.33 & HS LSD $=0.757$ & \\
\hline $\mathrm{CL} \times \mathbf{C S} \times \mathbf{H S}$ & & & & $\mathrm{LSD}=2.273$ & \\
\hline Hs $\left(\mathrm{kmh}^{-1}\right)$ & 2.17 & 3.00 & 3.49 & $\mathrm{CL} \times \mathrm{H} \mathrm{s}$ & \\
\hline \multicolumn{6}{|l|}{ CL $(\mathrm{cm})$} \\
\hline 2.0 & 30.89 & 29.00 & 27.0 & $\mathrm{LSD}=1.235$ & \\
\hline 1.5 & 29.56 & 28.56 & 27.56 & & \\
\hline 1.25 & 30.11 & 28.78 & 27.44 & & \\
\hline $\mathbf{C S} \times \mathbf{H s}$ & LSD $=1.363$ & & & CS means LSD $=\mathrm{Ns}$ & \\
\hline \multicolumn{6}{|l|}{ CS (rpm) } \\
\hline 700 & 30.11 & 28.33 & 27.22 & 28.56 & \\
\hline 900 & 30.0 & 28.89 & 27.89 & 28.93 & \\
\hline 1100 & 30.44 & 29.22 & 26.89 & 28.85 & \\
\hline
\end{tabular}

Table 4: The means of threshing index

\begin{tabular}{|c|c|c|c|c|c|}
\hline \multirow[b]{2}{*}{ CL (cm)/CS (rpm) } & \multicolumn{3}{|l|}{ Hs $\left(\mathrm{kmh}^{-1}\right)$} & \multirow{2}{*}{$\begin{array}{l}\mathrm{CL} \times \mathrm{Cs} \\
\mathrm{LSD}=18.13\end{array}$} & \multirow{2}{*}{$\begin{array}{l}\text { CL means } \\
\text { LSD }=\text { Ns }\end{array}$} \\
\hline & 2.17 & 3.0 & 3.49 & & \\
\hline \multicolumn{6}{|l|}{2.0} \\
\hline 700 & 281.0 & 121.3 & 190.30 & 227.9 & 292.6 \\
\hline 900 & 404.3 & 273.0 & 221.70 & 299.7 & \\
\hline 1100 & 459.7 & 325.0 & 266.00 & 350.2 & \\
\hline \multicolumn{6}{|l|}{1.5} \\
\hline 700 & 298.3 & 218.3 & 201.30 & 239.3 & 287.7 \\
\hline 900 & 368.7 & 251.3 & 236.70 & 285.6 & \\
\hline 1100 & 418.0 & 315.7 & 281.30 & 338.3 & \\
\hline \multicolumn{6}{|l|}{1.25} \\
\hline 700 & 320.3 & 228.3 & 176.30 & 239.0 & 289.4 \\
\hline 900 & 339.0 & 273.3 & 235.70 & 282.7 & \\
\hline 1100 & 476.9 & 306.4 & 257.30 & 346.6 & \\
\hline Hs means & 373.9 & 366.2 & 229.60 & $\mathrm{LSD}=7.92 \mathrm{HS}$ & \\
\hline $\mathrm{CL} \times \mathrm{CS} \times \mathrm{HS}$ & & & & LSD $=25.80$ & \\
\hline Hs $\left(\mathrm{kmh}^{-1}\right)$ & 2.17 & 3.0 & 3.49 & $\mathrm{CL} \times \mathrm{Hs}$ & \\
\hline \multicolumn{6}{|l|}{ CL $(\mathrm{cm})$} \\
\hline 2.0 & 381.7 & 270.1 & 226.00 & $\mathrm{LSD}=14.27$ & \\
\hline 1.5 & 361.7 & 261.8 & 239.40 & & \\
\hline 1.25 & 378.4 & 266.7 & 223.10 & & \\
\hline $\mathrm{CS} \times \mathrm{Hs}$ & LSD $=15.49$ & & & CS means LSD $=11.54$ & \\
\hline \multicolumn{6}{|l|}{ CS (rpm) } \\
\hline 700 & 299.9 & 217.0 & 189.30 & 235.4 & \\
\hline 900 & 370.7 & 265.9 & 231.30 & 289.3 & \\
\hline 1100 & 451.2 & 315.7 & 268.20 & 345.0 & \\
\hline
\end{tabular}

indicates that the relationship between threshing index and combine harvesters speed is not linear. The reason for the mentioned phenomena is attributed to the decrease in threshing intensity as the feed rate increases which is highly correlated with combine harvester speed. However, the relationship between threshing cylinder speed and threshing index is almost linear. Hence, the change in threshing index is approximately the same as levels of 
Table 5: The means of feed rate

\begin{tabular}{|c|c|c|c|c|c|}
\hline \multirow[b]{2}{*}{ CL (cm)/CS (rpm) } & \multicolumn{3}{|l|}{ Hs $\left(\mathrm{kmh}^{-1}\right)$} & \multirow{2}{*}{$\begin{array}{l}\mathrm{CL} \times \mathrm{Cs} \\
\mathrm{LSD}=\mathrm{Ns}\end{array}$} & \multirow{2}{*}{$\begin{array}{l}\text { CL means } \\
\mathrm{LSD}=\mathrm{Ns}\end{array}$} \\
\hline & 2.17 & 3.0 & 3.49 & & \\
\hline \multicolumn{6}{|l|}{2.0} \\
\hline 700 & 5.572 & 7.499 & 8.34 & 7.198 & 7.249 \\
\hline 900 & 5.143 & 7.514 & 8.447 & 7.032 & \\
\hline 1100 & 5.529 & 7.707 & 9.304 & 7.513 & \\
\hline \multicolumn{6}{|l|}{1.5} \\
\hline 700 & 5.415 & 7.297 & 7.848 & 6.854 & 7.313 \\
\hline 900 & 5.704 & 8.187 & 8.575 & 7.489 & \\
\hline 1100 & 5.071 & 7.933 & 8.789 & 7.598 & \\
\hline \multicolumn{6}{|l|}{1.25} \\
\hline 700 & 5.045 & 7.221 & 8.911 & 7.059 & 7.400 \\
\hline 900 & 6.133 & 7.495 & 8593 & 7.407 & \\
\hline 1100 & 5.340 & 8.203 & 9.655 & 7.733 & \\
\hline Hs means & 5.571 & 7.673 & 8.718 & LSD $=0.2044$ & \\
\hline $\mathbf{C L} \times \mathbf{C S} \times \mathbf{H S}$ & & & & LSD $=\mathbf{0 . 6 9 2 7}$ & \\
\hline Hs $\left(\mathrm{kmh}^{-1}\right)$ & 2.17 & 3.000 & 3.49 & $\mathrm{CL} \times \mathrm{Hs}$ & \\
\hline \multicolumn{6}{|l|}{ CL (cm) } \\
\hline 2.0 & 5.476 & 7.373 & 8.697 & $\mathrm{LSD}=0.380$ & \\
\hline 1.5 & 5.730 & 7.806 & 8.404 & & \\
\hline 1.25 & 5.506 & 7.640 & 9.249 & & \\
\hline CS $\times$ Hs & LSD $=0.4186$ & & & CS means LSI & \\
\hline \multicolumn{6}{|l|}{ CS (rpm) } \\
\hline 700 & 5.405 & 7.339 & 8.366 & 7.037 & \\
\hline 900 & 5.660 & 7.732 & 8.538 & 7.310 & \\
\hline 1100 & 5.647 & 7.948 & 9.249 & 7.615 & \\
\hline
\end{tabular}

threshing cylinder speed change. As seen in the Table 4, the binary and triple interactive effects are significant with a note that the variations were recognized between the experimental factors levels and between the parameters within the same levels.

Feed rate: The Analysis of Variance (ANOVA) shows a significant variation in the feed rate as the combine harvester speed factor varies at $\mathrm{p} \leq 0.01$. The combine harvester speed of $3.49 \mathrm{kmh}^{-1}$ was achieving the highest feed rate that was $8.7 \mathrm{kgsec}^{-1}$ when the rice residue height left in the field was $30.19 \mathrm{~cm}$ Table 5. While the slow speed of $2.17 \mathrm{kmh}^{-1}$ resulted in lower feed rate value that was $5.5 \mathrm{kgsec}^{-1}$ when the residue height was $27.33 \mathrm{~cm}$.

The reason for this is due to the increase in the number of plants covered by the cutter bar as a result of increasing the combine speed and the wide area harvested compared to the slow speed. These results correspond to the result found by Osueke (2014). The other factors either do not have any effect as in the cylinder concave clearance or has little effect as in the speed of the threshing cylinder. Even though, the origins of variation of the feed rate are the crop density, the grain yield at the desired harvest moisture content, the height of cut and the actual harvest width, the combine harvester speed remains the main source of variation that determine the value of the feed rate. That is because of the interaction between the combine harvester speed and the mentioned parameters during harvesting or these parameters are the components of feed rate equation. The binary interaction between the concave clearance and cylinder speed was not significant, however, the other interactions were significant because they interacted with most influential factor that is the combine harvester speed. It was worth mentioning that the increase in feed rate due to the change in clearance or the speed of the cylinder was changed with less impact compared to the change with the speed of combine harvester. The results shown in Table 5 showed that the effect of the triple interaction between the experimental factors in the feed rate parameter is significant. The highest feeding rate $9.65 \mathrm{kgsec}^{-1}$ was recorded by a combination of the highest speed of the $3.49 \mathrm{kmh}^{-1}$ with the highest cylinder speed of $1100 \mathrm{rpm}$ and the largest concave clearance $2.0 \mathrm{~cm}$. While the lowest feed rate of $5.045 \mathrm{kgsec}^{-1}$ was associated with lower speed of the combine harvester $2.17 \mathrm{kmh}^{-1}$, minimum cylinder speed $700 \mathrm{rpm}$ and the smallest concave clearance $1.25 \mathrm{~cm}$.

Threshing loss: The result in Table 6 illustrated that all factors of the experiment had a significant effect on threshing loss at $\mathrm{p} \leq 0.01$ whereas the lowest loss value achieved by the triple interaction consisting of the smallest concave clearance, the highest threshing cylinder speed and the lowest of combine harvester speed. While the highest value of loss achieved at the large concave clearance, the lowest threshing cylinder speed and the highest of combine harvester speed. Similar results were found by Osueke (2014). Table 7 explain the nature of the 
Table 6: The means of rice harvesting losses $\mathrm{kg} \mathrm{ha}^{-1}$

\begin{tabular}{|c|c|c|c|c|c|}
\hline \multirow[b]{2}{*}{ CL (cm)/CS (rpm) } & \multicolumn{3}{|l|}{ Hs $\left(\mathrm{kmh}^{-1}\right)$} & \multirow{2}{*}{$\begin{array}{l}\mathrm{CL} \times \mathrm{Cs} \\
\mathrm{LSD}=7.804\end{array}$} & \multirow{2}{*}{$\begin{array}{l}\text { CL means } \\
\mathrm{LSD}=6.914\end{array}$} \\
\hline & 2.17 & 3.0 & 3.49 & & \\
\hline \multicolumn{6}{|l|}{2.0} \\
\hline 700 & 47.71 & 104.35 & 111.42 & 104.50 & 82.84 \\
\hline 900 & 70.99 & 85.14 & 95.50 & 83.88 & \\
\hline 1100 & 51.79 & 62.66 & 65.94 & 60.13 & \\
\hline \multicolumn{6}{|l|}{1.5} \\
\hline 700 & 60.64 & 76.60 & 83.12 & 73.45 & 49.72 \\
\hline 900 & 44.72 & 47.46 & 47.75 & 46.64 & \\
\hline 1100 & 28.04 & 28.30 & 30.82 & 29.05 & \\
\hline \multicolumn{6}{|l|}{1.25} \\
\hline 700 & 37.84 & 43.20 & 55.23 & 45.42 & 32.64 \\
\hline 900 & 28.29 & 31.00 & 32.84 & 30.71 & \\
\hline 1100 & 18.39 & 21.49 & 25.84 & 21.79 & \\
\hline Hs means & 48.71 & 55.58 & 60.90 & HS LSD = 3.513 & \\
\hline $\mathbf{C L} \times \mathbf{C S} \times \mathbf{H S}$ & & & & LSD = 11.221 & \\
\hline Hs $\left(\mathrm{kmh}^{-1}\right)$ & 2.17 & 3.00 & 3.49 & $\mathrm{CL} \times \mathrm{Hs}$ & \\
\hline \multicolumn{6}{|l|}{ CL (cm) } \\
\hline 2.0 & 73.50 & 84.05 & 90.96 & $\mathrm{LSD}=7.491$ & \\
\hline 1.5 & 44.47 & 50.79 & 53.90 & & \\
\hline 1.25 & 28.18 & 31.90 & 37.85 & & \\
\hline $\mathbf{C S} \times \mathbf{H s}$ & LSD $=0.4186$ & & & CS means LSD $=4.00$ & \\
\hline \multicolumn{6}{|l|}{ CS (rpm) } \\
\hline 700 & 65.40 & 74.72 & 83.24 & 74.46 & \\
\hline 900 & 48.00 & 54.54 & 58.70 & 53.75 & \\
\hline 1100 & 32.74 & 37.48 & 40.72 & 36.99 & \\
\hline
\end{tabular}

Table 7: The maximum and minimum losses values as related to feed rate, threshing cylinder impact and threshing index

\begin{tabular}{|c|c|c|c|c|c|c|c|}
\hline \multirow{2}{*}{$\begin{array}{l}\text { Combine } \\
\text { advance } \\
\left(\mathrm{msec}^{-1}\right)\end{array}$} & \multirow[b]{2}{*}{$\begin{array}{l}\text { Feed rate } \\
\left(\mathrm{kgsec}^{-1}\right)\end{array}$} & \multicolumn{3}{|c|}{ Threshing cylinder impact } & \multirow[b]{2}{*}{$\begin{array}{c}\text { Threshing } \\
\text { index }\end{array}$} & \multirow[b]{2}{*}{$\begin{array}{c}\text { Concave } \\
\text { clearance }(\mathrm{cm})\end{array}$} & \multirow[b]{2}{*}{$\begin{array}{l}\text { Losses } \\
\left(\mathrm{kgha}^{-1}\right)\end{array}$} \\
\hline & & $\begin{array}{l}\text { Cylinder } \\
\text { (speed rpm) }\end{array}$ & $\begin{array}{l}\text { Number of cylinder } \\
\text { bars strike per second }\end{array}$ & $\begin{array}{l}\text { Number of cylinder } \\
\text { teeth strike per second }\end{array}$ & & & \\
\hline 0.603 & 5.34 & 18.33 & 146.7 & 1906.7 & 474.0 & 1.25 & 18.39 \\
\hline 0.97 & 8.34 & 11.70 & 93.3 & 1213.3 & 190.3 & 2.00 & 111.42 \\
\hline
\end{tabular}

triple interaction and the effect of the related parameters in determining the final amount of threshing loss. In case of the lowest loss value the combine harvester advanced $0.6 \mathrm{msec}^{-1}$ to feed the combine threshing unit with a moderate quantity of rice crop biomass equal to $5.34 \mathrm{kgsec}^{-1}$. This rice crop biomass was exposed to two effects, one of which is the effect of a pre-prepared threshing cylinder speed. With regard to this effect, the threshing cylinder speed was calibrated at $18.38 \mathrm{rev} \mathrm{sec}^{-1}$ which in turn exposes the rice crop biomass to 146.7 and 1907.7 strike $\mathrm{sec}^{-1}$ of the cylinder bars and cylinder teeth, respectively Table 7 . The other effect is the total effect of the external surface area of the threshing cylinder relative to the combine speed during harvesting. This effect is represented by the threshing index and its value was 476 . It should be noted that the threshing index represents the intensity of threshing when the threshing index is high, the intensity of the threshing is also high and vice versa. In case of 476 threshing index means the intensity of threshing is high. On the other hand, the highest value of loss was obtained when the combine advanced $0.97 \mathrm{msec}^{-1}$. It was considered relatively high speed to feed the threshing unit with a high quantity of the rice crop equivalent to $8.35 \mathrm{~kg} \cdot \mathrm{sec}^{-1}$. Table 7 revealed that the threshing cylinder speed was $11.7 \mathrm{rev} \mathrm{sec}{ }^{-1}$. This speed

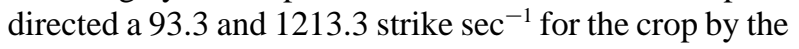
bars of the cylinder and the teeth of the cylinder bars, respectively. As illustrated by the same table the decrease in threshing index to 190 accompanied by a thick layer of the crop (as a result of wide concave clearance) reduced the intensity of threshing and increased threshing loss. Therefore, it can be concluded that the most influential parameters in determining the amount of loss were the feed rate and threshing index, both of them relied on the combine advancement in the field. This conclusion is proved by the strong correlation between the mentioned above parameters and threshing loss. The statistical analysis indicated that the threshing loss parameter was significantly and positively correlated with feed rate while negatively correlated with threshing index at $\mathrm{p} \geq 0.01$. That is a $56 \%$ increase in the lowest feed rate and $60 \%$ decrease from the highest threshing index led to 6 fold increase in threshing loss. Table 7 also shows the effect of threshing intensity on rice biomass entering the cage of impact. The rice biomass exposed to severe beating, pulling and friction from the cylinder bars and teeth makes it easier to separate grain from panicles. This may vary with the speed of the cylinder. Anyway, the ease of 
separation of grain is because of the pressure of the threshing cylinder accompanied by increase in grain damage. This phenomenon has made specialists call for reconciling between threshing loss of grain and grain damage during harvesting.

The results indicated that the binary interactions were significant with indication that highest differences were found between the speed of the threshing cylinder and concave clearance means. The triple interaction was also significant and the synthesis consisting of the smallest concave clearance $1.25 \mathrm{~cm}$, the highest threshing cylinder speed $1100 \mathrm{rpm}$ and the minimum speed of the combine harvester $2.17 \mathrm{kmh}^{-1}$ gave $18.34 \mathrm{kgh}^{-1}$ which was the least value of threshing loss at all in this research.

\section{CONCLUSION}

Based on the finding of the study, it is concluded that all experiment factors had a significant effect in determining the amount of threshing losses and varied in terms of the influence with respect to the height of cut, threshing index and feed rate. The results demonstrated that the threshing index and feed rate played a major role in quantifying threshing losses. Despite the gain achieved by reducing the amount of threshing losses as a result of increasing the threshing cylinder speed and reducing concave clearance but the samples taken confirmed existence of little grains peeling which needs further researches and investigations.

\section{REFERENCES}

Ahmad, T., Z. Ali and H.S. Mahmood, 2017. Factors causing low head rice recovery in combine-harvested paddy. Sci. Technol. Dev., 36: 84-90.

Al-Mosawi, A.A., 2007. Assessment of rice mechanical harvesting losses and grain quality of effect evaluation of the lodged rice lifter on cutterbar performance. Ph.D Thesis, University of Baghdad, Iraq.
Andrews, S.B., 1993. Effect of combine operating parameters on harvest loss and quality in rice. MSc Thesis, University of Arkansas, Fayetteville, Arkansas.

Fu, J., Z. Chen, L.J. Han and L.Q. Ren, 2018. Review of grain threshing theory and technology. Intl. J. Agric. Biol. Eng., 11: 12-20.

Mohd, A.A., A.R. Omar, E.A. Mutasim and I.D. Mamou, 1997. On farm evaluation of combine harvester losses in the geezer she in the Sudan. JAMA, 28: 23-25.

Oduma, O., J.C. Edeh and C.C. Eze, 2015. Comperative performance of a locally developed groundnut decorticator with an imported kirlosker decorticator. Intl. J. Eng. Technol., 5: 205-2011.

Olaye, A.R.I.B., J. Moreira, J. Hounhouigan and S.K. Amponsah, 2016. Effect of threshing drum speed and crop weight on paddy grain quality in axial-flow thresher (ASI). J. Multidisciplin. Eng. Sci. Technol., 3: 3716-3721.

Osueke, E.C.O., 2014. Study of the influence of crop, machine and operating parameters on performance of cereal threshers. Intl. J. Eng. Res. Dev., 7: 1-9.

Rad, D.M., 2004. Grain Harvester Machine: Tractors and Agricultural Machinery. 5th Edn., Abuali Sina University Press, Hamedan, Iran pp: 276-400.

Siebenmorgen, T.J., S.B. Andrews and P.A. Counce, 1994. Relationship of the height rice is cut to harvesting test parameters. Trans. ASAE., 37: 67-69.

Tang, Z., Y. Li and Z. Liang, 2016. Optimal parameters prediction and control of rice threshing for longitudinal axial threshing apparatus. Trans. Chin. Soc. Agric. Eng., 32: 70-76.

Taylor, K.R. and M.D. Schroch, 1995. Harvesting wheat cooperative extension service. Master Thesis, Department of Biological and Agricultural Engineering, Kansas State University, Manhattan, Kansas. 